\title{
A 65-year-old Female With a Rapidly Growing Painless Occipital Mass Encircling the Foramen Magnum
}

\author{
Harry Haynes ${ }^{\mathrm{a}, \mathrm{d}}$, Dan Taylor ${ }^{\mathrm{b}}$, Nicki Cohen ${ }^{\mathrm{c}}$
}

\begin{abstract}
Solitary plasmacytoma of bone is a rare disorder accounting for $5-10 \%$ of plasma cell dyscrasias with most patients progressing to myeloma. Here the authors present a case of a 65-year-old female who presented with a hard occipital lump. An MRI demonstrated extensive mass distortion of the right cerebellar hemisphere. This was biopsied showing a cluster of plasma cells with discohesive, monomorphic cells, cytoplasmic clearing or "hoff", and characteristic clock-face nuclei. The patient had no symptoms other than neck pain, headaches and the hard occipital mass. Solitary plasmacytoma of bone is only diagnosed where there is no evidence to support myeloma as a diagnosis, and investigations are tailored towards this. Radiotherapy is the mainstay of treatment and patients should be monitored for the development of myeloma.
\end{abstract}

Keywords: Plasmacytoma; Neurosurgery; Neuropathology

\section{Introduction}

Solitary plasmacytoma of bone is a monoclonal mass of plasma cells arising from bone without the systemic features of multiple myeloma. In contrast to extramedullary plasmacytoma, it tends to affect the axial skeleton. The disease is rare occurring at a rate of $0.15 / 100,000$ person years [1] Common clinical presentations include bone pain and pathological fracture of the affected bones. There may be neurological symptoms, usually as a result of vertebral collapse. Rarely, as is demonstrated here, a palpable mass may be felt

\footnotetext{
Manuscript accepted for publication October 25, 2012

${ }^{a}$ Dept of Neurosciences, Frenchay Hospital, Bristol, UK

${ }^{\mathrm{b}}$ Dept of Medicine, Bath Royal United Hospital, UK

${ }^{\mathrm{c}}$ Dept of Neuropathology, Frenchay Hospital, Bristol, UK

${ }^{\mathrm{d}}$ Corresponding author: Harry Haynes, Dept of Neurosciences,

Frenchay Hospital, Bristol, BS16 1UU, UK.

Email: harryrhaynes@doctors.org.uk

doi: http://dx.doi.org/10.4021/jmc934w
}

resulting from distortion of soft tissue and surrounding structures [2]. The following case demonstrates a radiologically extensive cranial disease process with little in the way of neurological signs.

\section{Case Report}

A 65-year-old lady presented with an 8-week history of a hard right sided occipital mass, neck pain and headaches. She had no past medical history and was on no regular medications. Physical examination including full neurological examination was normal apart from the presence of the nontender mass.

Blood tests showed normal haematological, biochemical and inflammatory markers. Specifically there was no evidence of anaemia, raised calcium or renal impairment.

MRI head with gadolinium (Fig. 1) showed a large posterior fossa skull base mass almost encircling the foramen magnum with distortion of the right cerebellar hemisphere. Subsequent biopsy of the mass revealed sheets of discohesive, monomorphic plasma cells, immunopositive to CD138 with characteristic clock-face nuclei (Fig. 2). Serum electrophoresis, immunofixation and immunoglobulin levels were normal. Urine immunofixation showed kappa monoclonal free light chains (Bence-Jones Protein). CT scanning of the patient's chest, abdomen and pelvis revealed no further abnormalities. A bone marrow biopsy showed no evidence of myeloma. A diagnosis of solitary plasmacytoma of bone was made.

\section{Discussion}

Solitary plasmacytoma of bone (SPB) can only be diagnosed once other differentials have been excluded; these include multiple myeloma, solitary extramedullary plasmacytoma, plasma cell lymphoma, POEMS syndrome and metastatic carcinoma. Investigations that should be performed on all patients with a biopsy proven plasma cell tumour include FBC, $U$ and E, calcium, full myeloma screen (serum and urine protein electrophoresis and immunofixation, serum 


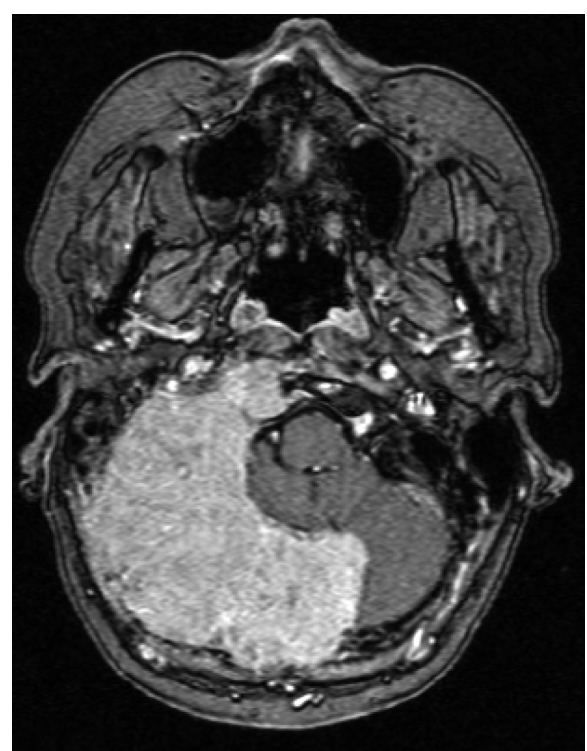

Figure 1. MRI Head with Gadolinium: axial section with level at medulla oblongata.

immunoglobulin levels, serum free light chain assay and full skeletal survey), MRI pelvis/spine and a bone marrow biopsy. There must be no other lytic skeletal lesions and no bone marrow involvement [3]. A small monoclonal protein can be present in up to $75 \%$ of cases and this does not exclude the diagnosis of SPB but can carry prognostic relevance if persistent after treatment [4]. Any anaemia, renal failure or hypercalcaemia that is present must have a cause not related to a possible plasma cell disorder.

If the bone marrow of patients suspected of having SPB contains $>10 \%$ clonal plasma cells then they should be diagnosed as having myeloma. If there are clonal plasma cells present but $<10 \%$ then they should be diagnosed as having SPB plus monoclonal gammopathy of undetermined significance, assuming no other myeloma organ or tissue effects [3].

SPB is distinguished from extramedullary plasmacytoma mostly by means of location. SPB tends to affect the axial skeleton (areas of high haematopoietic activity) whereas extramedullary plasmacytoma has a tendency to form in the soft tissue of the head and neck, especially the upper respiratory tract [5]. Extramedullary plasmacytomas have less of a tendency to progress to myeloma and less than $25 \%$ of patients demonstrate a serum or urine paraprotein [3].

When biopsied, classically plasma cell tumours show discohesive and monomorphic cells with cytoplasmic clearing or "hoff", and characteristic clock-face nuclei, with dispersed peripheral aggregates of chromatin. Malignant cells have enlarged nucleoli. CD138 (syndecan 1) is considered a reliable marker [6].

Radical radiotherapy is the treatment of choice for solitary plasmacytomas. Surgery is generally not indicated however decompressive laminectomy and spinal fusion can
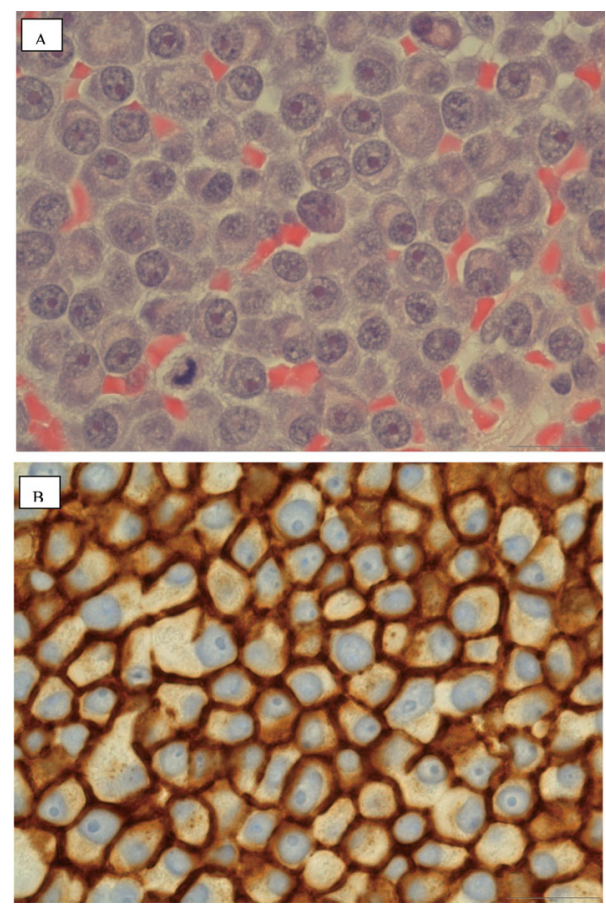

Figure 2. A: $\times 100 \mathrm{H}$ and $\mathrm{E} ; \mathrm{B}: \times 100$ Immunohistochemistry: CD138 positive cells stain brown.

be considered in patients at risk of spinal instability [5]. No evidence of occipital-cervical instability was found in our patient and radiotherapy alone was given as the first line treatment.

Current available data suggests that most patients will go on to develop myeloma (51\% at 5 years and $72 \%$ at 10 years [7]). The median time to development of myeloma is 21 months with increasing age being a predictive factor. A monoclonal band (detected at time of diagnosis) that is present 1 year after treatment has been postulated as an adverse prognostic indicator with regards to development of multiple myeloma [4].

\section{Acknowledgement}

Nil.

\section{References}

1. Dores GM, Landgren O, McGlynn KA, Curtis RE, Linet MS, Devesa SS. Plasmacytoma of bone, extramedullary plasmacytoma, and multiple myeloma: incidence and survival in the United States, 1992-2004. Br J Haematol. 2009;144(1):86-94.

2. Bataille R, Sany J. Solitary myeloma: clinical and prognostic features of a review of 114 cases. Cancer. 
1981;48(3):845-851.

3. Hughes M, Soutar R, Lucraft $H$ et al. Guidelines on the diagnosis and management of solitary plasmacytoma of bone, extramedullary plasmacytoma and multiple solitary plasmacytomas: 2009 update. London (UK): British Committee for Standards in Haematology.

4. Wilder RB, Ha CS, Cox JD, Weber D, Delasalle K, Alexanian R. Persistence of myeloma protein for more than one year after radiotherapy is an adverse prognostic factor in solitary plasmacytoma of bone. Cancer. 2002;94(5):1532-1537.
5. Kilciksiz S, Karakoyun-Celik O, Agaoglu FY, Haydaroglu A. A review for solitary plasmacytoma of bone and extramedullary plasmacytoma. ScientificWorldJournal. 2012;2012:895765.

6. Singh AD, Chacko AG, Chacko G, Rajshekhar V. Plasma cell tumors of the skull. Surg Neurol. 2005;64(5):434438; discussion 438-439.

7. Knobel D, Zouhair A, Tsang RW, Poortmans P, Belkacemi Y, Bolla M, Oner FD, et al. Prognostic factors in solitary plasmacytoma of the bone: a multicenter Rare Cancer Network study. BMC Cancer. 2006;6:118. 